\title{
RELATIONSHIP BETWEEN FILTRATION EFFICIENCY, RESISTANCE AND GRAMMES PER SQUARE METRE, THE THICKNESS, THE FIBER DIAMETER AND THE POROSITY OF ELECTROSPUN NANOFIBRES NON-WOVEN MEMBRANE
}

\section{RUDONG CHEN ${ }^{1}$, TING WANG ${ }^{1}$, WENXIA DONG ${ }^{1}$, YING CHEN $2,3,4$, TIANDI PAN ${ }^{2}$ and YONG LIU ${ }^{2}$}

${ }^{1}$ Department of Mathematics

Tianjin Polytechnic University

No. 399, Binshuixi Street

Xiqing District, Tianjin, 300387

P. R. China

e-mail: chenrd@tjpu.edu.cn

${ }^{2}$ Department of Textile

Tianjin Polytechnic University

No. 399, Binshuixi Street

Xiqing District, Tianjin, 300387

P. R. China

${ }^{3}$ The Higher Occupation Education Department

Tianjin University of Technology and Education

Tianjin, 300222

P. R. China

2010 Mathematics Subject Classification: 74E30, 68U10, 62J05.

Keywords and phrases: electrospun nanofibres non-woven membrane, filtration efficiency, resistance, grammes per square metre, the thickness of the fiber membrane, the fiber diameter, the porosity, SAS.

Received June 30, 2018; Revised July 30, 2018

(ㄷ) 2018 Scientific Advances Publishers 
${ }^{4}$ Statistical Research Institute

Naikai University

Tianjin, 300071

P. R. China

\begin{abstract}
In this paper, based on the correlation analysis, the relationship between the filtration efficiency, resistance of electrospun nanofibres non-woven membrane and grammes per square metre of the fiber membrane, the thickness of the fiber membrane, the fiber diameter, and the porosity of the fiber membrane are studied by SAS software. Our analysis results show that the changes of the filtration efficiency and resistance are obvious with the change of thickness, the change of diameter and the change of porosity. As the grammes per square metre of the fiber membrane increases, the thickness of the fiber membrane increases, the fiber diameter decreases and the porosity of the fiber membrane decreases, resulting in an increase in filtration efficiency and an increase in resistance.
\end{abstract}

\title{
1. Introduction
}

Basic principle of electrostatic spinning is that a high voltage static electricity is used to create electrically charged jet of polymer solution or melt, the solvent in the jet volatilizes or the melt solidifies during injection and is collected as a web of small fibers in the collector. Nonwoven fabric is a kind of microporous material with a three-dimensional network structure. It is a kind of excellent filter material. Its unique three-dimensional network structure makes it have more obvious advantages than the woven fabric and knitted fabric in terms of filtration [1-5]. In addition, due to the diversity of processing methods of nonwovens, the optimum fiber curved system can be formed according to the specific use of the filter material, making the production of filter materials more reasonable and economical [6, 7].

Filtration material is a common material used in daily life and it is a very important unit in many production fields. Filtration materials are playing an important role in air purification, raw material purification, mining and so on and has become an indispensable part of modern 
industry $[8,9]$. In recent years, filter materials are widely used in food, chemical, military, automobile, metal processing, medicine and hygiene, etc [5, 10-13]. Non-woven fabric filter material is a novel fiber filter material, which has the advantages of high filtration efficiency, low resistance and great dust holding capacity. Filtration efficiency is an important performance index of the filter material, and there are many factors influencing the filtration efficiency, such as non-woven fabric structure, particle size and shape [5, 8]. This paper mainly discusses the influence of grammes per square metre, the thickness of the fiber membrane, the fiber diameter, and the porosity of the fiber membrane on filtration efficiency and resistance electrospun nanofibres non-woven membrane.

\section{Experiments and Tests}

\subsection{Experiments}

\subsubsection{Experimental materials}

Polyvinyl alcohol (PVA) with a relative molecule weight (Mn) of $84000 \sim 89000$, alcoholysis degree of $86 \sim 89 \mathrm{~mol} \%$ and the average degree of polymerization 1700 1800 was purchased from Changchun Petrochemical Co., Ltd., Taiwan.

\subsubsection{Experimental apparatus}

DXES-01 automatic electrospinning machine, produced by Shanghai Dongxiang Nano Technology Co., Ltd.; TSI 8130 Automatic Filtration Tester, Tsai Sai Central Instrument Trade Co., Ltd. (Beijing); TM 3030 Desktop Scanning Electron Microscopy, Japan Hitachi Agency, Hitachi High-Technologies Nagano Office; Digital Display Thickness Gauge, Deqing Shengtai Electronic Technology Co., Ltd. (Zhejiang); Electronic balance, Baoheng Technology Co., Ltd. (Shanghai). 


\subsubsection{Spinning solution preparation}

Polyvinyl alcohol was dissolved in distilled water and formulated into a polyvinyl alcohol solution with a concentration of $12 \%$. The resulting mixed solution was stirred in a water bath at $80^{\circ} \mathrm{C}$ for $1 \mathrm{~h}$ until a uniform solution was formed, and then it was statically defoamed.

\subsubsection{Sample preparation}

At room temperature, the prepared spinning solution was poured into four $5 \mathrm{~mL}$ syringes with a needle diameter of $1.2 \mathrm{~mm}$. From previous studies, there are five process parameters for fabricating electrospun nanofiber non-wovens including 90 minutes for the spinning time, $12 \%$ for the solution concentration, and the needle-to-collector distance $(\mathrm{cm})$ taken as 11, 13, 15, 17, 19, applied voltage $(\mathrm{kV})$ taken as 15, 18, 20, 23, 26 ; volume flow rate $(\mathrm{mL} / \mathrm{h})$ taken as $0.5,0.7,1,1.2,1.5$. To ensure the generality of the experiment and to avoid too many experiments, we adopted an orthogonal experiment method and added five more experiments based on orthogonal experiment, as shown in Table 1 and Table 2. 
RELATIONSHIP BETWEEN FILTRATION EFFICIENCY ... 131

Table 1. Parameter design table

\begin{tabular}{|c|c|c|c|c|c|c|c|c|}
\hline 1 & 1 & 1 & 1 & & 16 & 3 & 3 & 5 \\
\hline 2 & 2 & 1 & 2 & & 17 & 4 & 3 & 1 \\
\hline 3 & 3 & 1 & 3 & & 18 & 5 & 3 & 2 \\
\hline 4 & 4 & 1 & 4 & & 19 & 1 & 4 & 4 \\
\hline 5 & 5 & 1 & 3 & & 20 & 2 & 4 & 5 \\
\hline 6 & 5 & 1 & 5 & & 21 & 3 & 4 & 1 \\
\hline 7 & 1 & 2 & 1 & & 22 & 4 & 4 & 2 \\
\hline 8 & & 2 & 2 & & 23 & 4 & 4 & 5 \\
\hline 9 & 2 & 2 & 3 & & 24 & 5 & 4 & 3 \\
\hline 10 & 3 & 2 & 4 & & 25 & 1 & 5 & 5 \\
\hline 11 & 4 & 2 & 5 & & 26 & 2 & 5 & 1 \\
\hline 12 & 5 & 2 & 1 & & 27 & 2 & 5 & 3 \\
\hline 13 & 1 & 3 & 3 & & 28 & 3 & 5 & 2 \\
\hline 14 & 2 & 3 & 4 & & 29 & 4 & 5 & 3 \\
\hline 15 & 3 & 3 & 2 & & 30 & 5 & 5 & 4 \\
\hline
\end{tabular}


Table 2. Experiment table

\begin{tabular}{|c|c|c|c|c|c|c|c|}
\hline No. & $\begin{array}{c}\text { Needle-to-collector } \\
\text { distance }(\mathrm{cm})\end{array}$ & $\begin{array}{c}\text { Applied } \\
\text { voltage } \\
(\mathrm{kV})\end{array}$ & $\begin{array}{c}\text { Volume } \\
\text { flow rate } \\
(\mathrm{mL} / \mathrm{h})\end{array}$ & No. & $\begin{array}{c}\text { Needle-to-collector } \\
\text { distance }(\mathrm{cm})\end{array}$ & $\begin{array}{c}\text { Applied } \\
\text { voltage } \\
(\mathrm{kV})\end{array}$ & $\begin{array}{c}\text { Volume } \\
\text { flow rate } \\
(\mathrm{mL} / \mathrm{h})\end{array}$ \\
\hline 1 & 11 & 15 & 0.5 & 16 & 15 & 20 & 1.5 \\
\hline 2 & 13 & 15 & 0.7 & 17 & 17 & 20 & 0.5 \\
\hline 3 & 15 & 15 & 1 & 18 & 19 & 20 & 0.7 \\
\hline 4 & 17 & 15 & 1.2 & 19 & 11 & 23 & 1.2 \\
\hline 5 & 19 & 15 & 1 & 20 & 13 & 23 & 1.5 \\
\hline 6 & 19 & 15 & 1.5 & 21 & 15 & 23 & 0.5 \\
\hline 7 & 11 & 18 & 0.5 & 22 & 17 & 23 & 0.7 \\
\hline 8 & 11 & 18 & 0.7 & 23 & 17 & 23 & 1.5 \\
\hline 9 & 13 & 18 & 1 & 24 & 19 & 23 & 1 \\
\hline 10 & 15 & 18 & 1.2 & 25 & 11 & 26 & 1.5 \\
\hline 11 & 17 & 18 & 1.5 & 26 & 13 & 26 & 0.5 \\
\hline 12 & 19 & 18 & 0.5 & 27 & 13 & 26 & 1 \\
\hline 13 & 11 & 20 & 1 & 28 & 15 & 26 & 0.7 \\
\hline 14 & 13 & 20 & 1.2 & 29 & 17 & 26 & 1 \\
\hline 15 & 15 & 20 & 0.7 & 30 & 19 & 26 & 1.2 \\
\hline
\end{tabular}




\subsection{Tests}

\subsubsection{Fiber diameter}

The surface of the sample was sprayed with gold under vacuum conditions. The SEM photos of PVA electrospun non-wovens were taken with TM-3030 scanning electron microscope, and the electron microscope diagrams of the samples were obtained.

VC++ software and the refined rotation image method are used to measure fiber diameter in this study. The refined rotation image method is a method to approximate the width of the object, which is applied to the differential knowledge in mathematics. As shown in Figure 1, the curve $S_{1}$ and the curve $S_{2}$ obtained by rotating the curve $S_{1}$ clockwise by $90^{\circ}$. Line $l_{1}$ is the tangent of $S_{1}$ at point $O$, line $l_{2}$ is the tangent of $S_{2}$ at point $O$, so $l_{1}$ is perpendicular to $l_{2}$. According to the differential principle, for any $\varepsilon$, there exists $\delta>0$, so that in the domain $O(0, \delta)$, there is $f\left(l_{1}\right)-f\left(l_{2}\right)<\varepsilon$. When $\delta$ is sufficiently small, $f\left(l_{1}\right) \approx f\left(l_{2}\right)$, where $f(l)$ represents the length function of the curve $l$ in the domain $O(0, \delta)$. For the object with smaller curvature, the width can be calculated by this method, as shown in Figure 2. Digital image processing techniques and mathematical morphology knowledge are needed to process images and calculate fiber diameters by using $\mathrm{VC}++$ computer software. First, the digital image processing technology is used to grayscale the sample image, and then the image is enhanced, and the binarization is made by selecting the appropriate threshold value to eliminate the noise processing, as shown in Figure 3. Second, the fiber structure is refined by the image thinning algorithm in mathematical morphology, as shown in Figure 3. A line is taken every 10 pixels, and each image takes 55 positions to measure the diameter of the fiber on the line of the corresponding pixel, and then the average value is taken. 


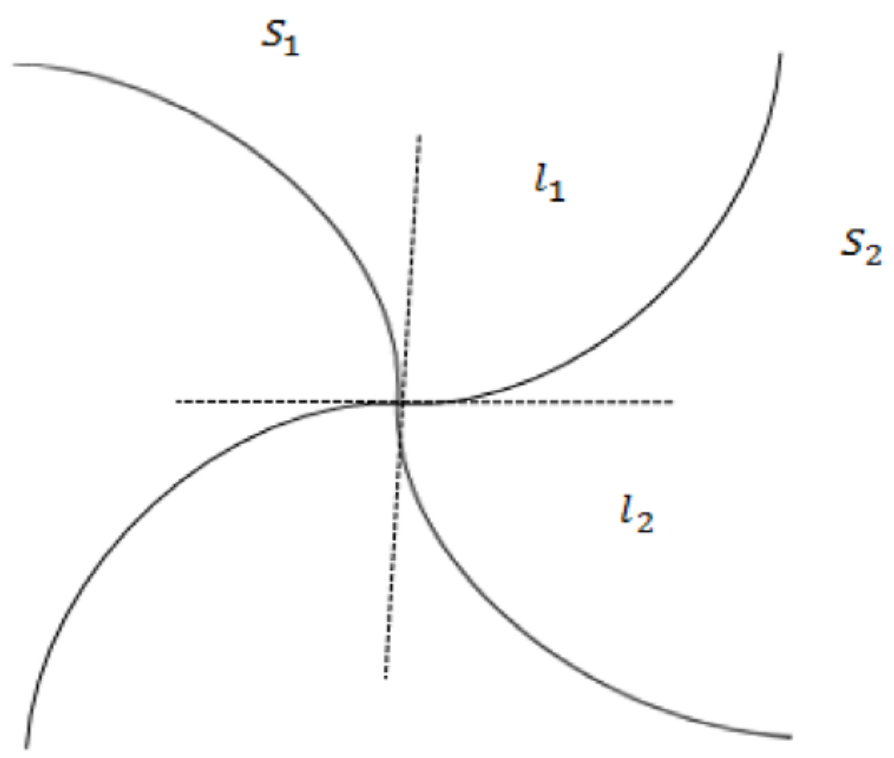

Figure 1. Curve rotation intersection.

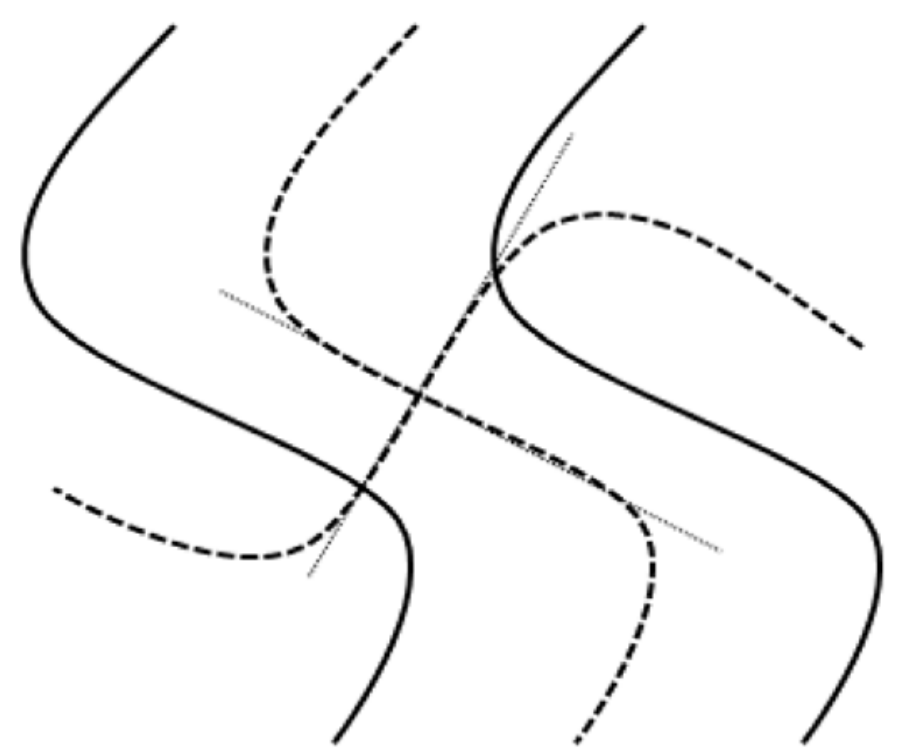

Figure 2. Approximate width measurement. 


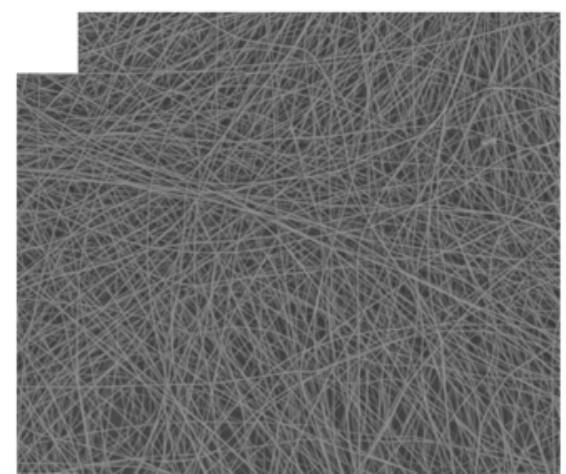

(a)

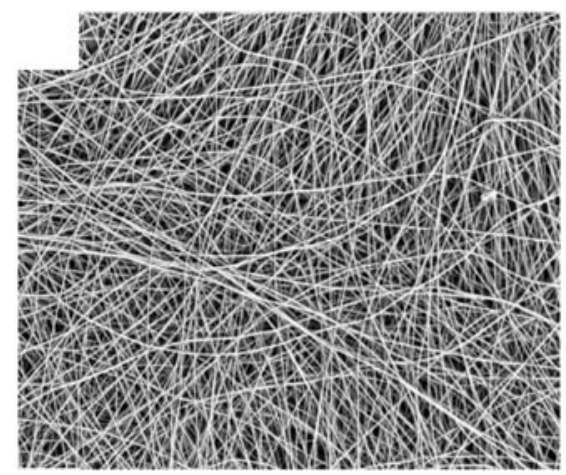

(c)

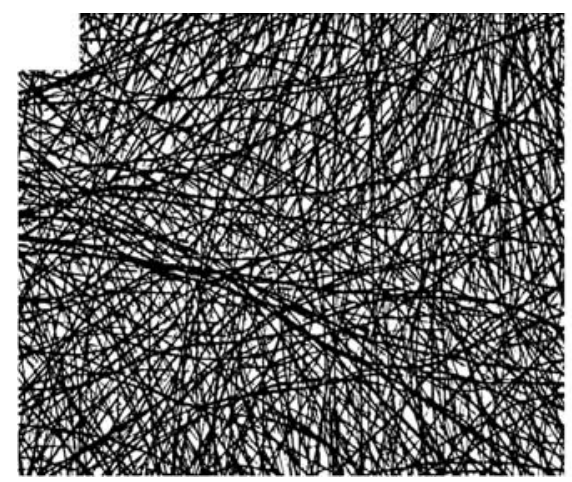

(e)

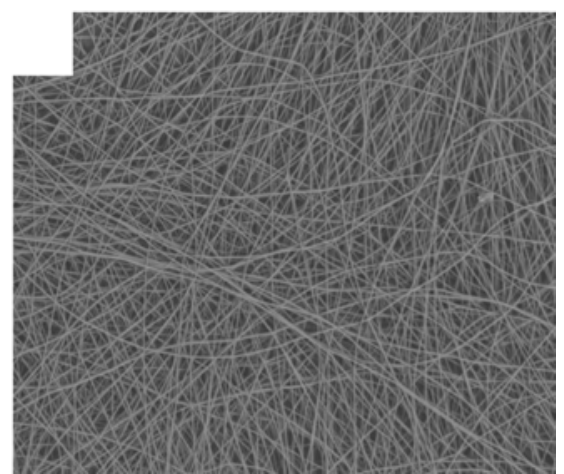

(b)

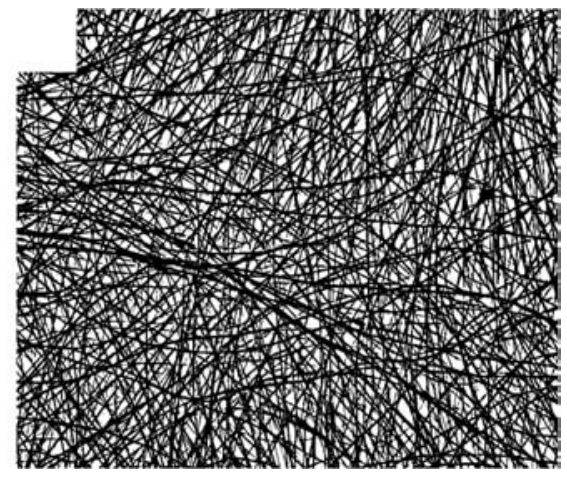

(d)

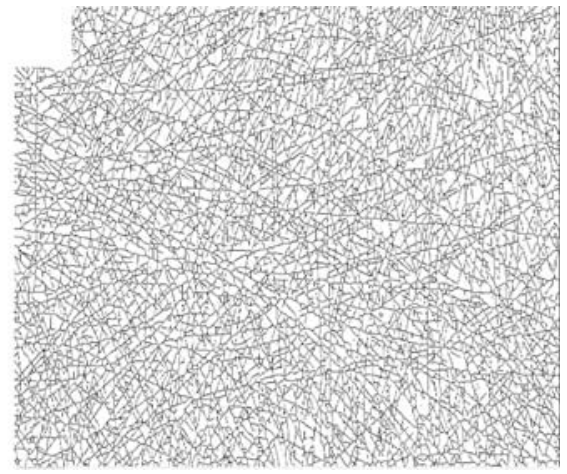

(f)

Figure 3. Comparison between each processed image and the original image: (a) the original image; (b) grayscale image; (c) enhanced image; (d) binary image; (e) denoising image; and (f) refined image. 


\subsubsection{Porosity of the fiber membrane}

Matlab software is mainly used to calculate the porosity of the samples in this article. First, the threshold is determined. In the photoshop software, the threshold command converts a grayscale or color image into a high-contrast black-and-white image. A certain color gradation can be specified as a threshold. All pixels $t$ brighter than the threshold are converted to white and all pixels darker than the threshold are converted to black. The SEM image of the sample is imported into photoshop and converted to a grayscale image. The threshold is adjusted, the image change is observed, and then the threshold is determined, as shown in Figure 4. In order to reduce the subjective error, the average threshold value of multi-person evaluation is used to calculate the porosity of nanofiber membrane in this paper. The best threshold of similarity between the processed image and the original image is chosen as the final threshold.

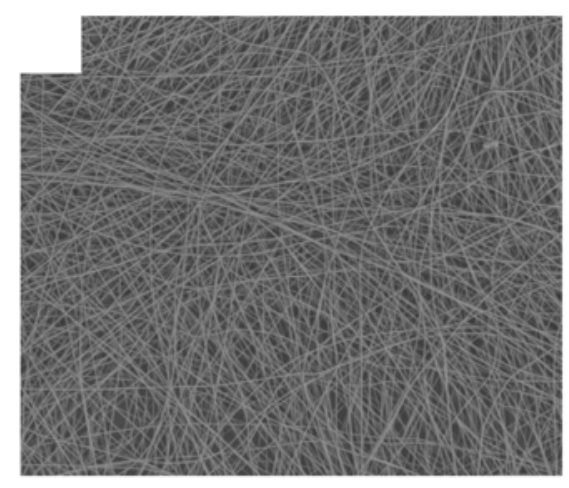

(a)

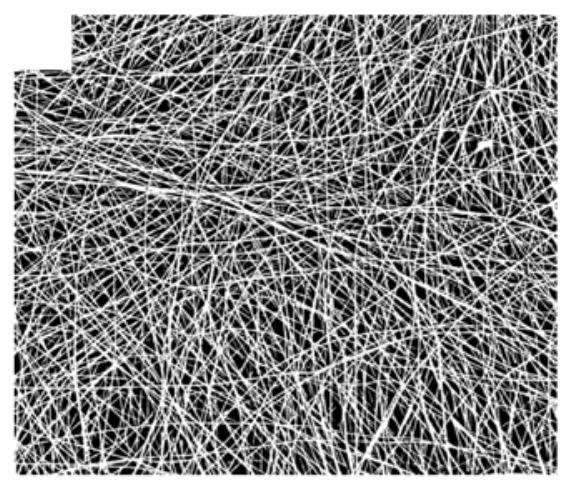

(b)

Figure 4. Comparison between the original image and threshold segmented sample image: (a) the original image; (b) threshold segmented image. 
Secondly, the number of pixel at each position of the sample image are obtained by using Matlab software, and the porosity of non-woven fabric can be calculated by formula (1) using the determined threshold.

$$
P(\%)=\left(1-\frac{n}{N}\right) \times 100,
$$

where $n$ is the number of white pixels, $N$ is the total number of pixels, and $P$ is the porosity of the nanofibre membrane.

\subsubsection{Filtration efficiency and resistance of electrospun nanofibres non-woven membrane}

The TSI8130 automatic filter tester was used for the measurement.

\subsubsection{Thickness of the fiber membrane}

Digital display gauge was used for the measurement. Four positions were measured for each sample, and the average value was obtained.

\subsubsection{Grammes per square metre of the fiber membrane}

The total weight of the receiving cloth and film was measured by using an accurate electronic balance of $0.0001 \mathrm{~g}$ and a sample size of $5 \times 5 \mathrm{~cm}$. The weight of the receiving cloth and the film was measured, and the average value of the twice film was taken to calculate the gram weight. 
Table 3. Test results

\begin{tabular}{|c|c|c|c|c|c|}
\hline No. & Porosity /\% & $\begin{array}{c}\text { Average } \\
\text { diameter /nm }\end{array}$ & No. & Porosity /\% & $\begin{array}{c}\text { Average } \\
\text { diameter /nm }\end{array}$ \\
\hline 1 & 46.25256 & 15.61163 & 16 & 42.69979 & 12.31041 \\
\hline 2 & 39.00588 & 13.259 & 17 & 44.81205 & 14.24199 \\
\hline 3 & 38.59959 & 14.87568 & 18 & 48.88883 & 18.17169 \\
\hline 4 & 41.95877 & 17.14878 & 19 & 37.2224 & 11.26738 \\
\hline 5 & 46.11507 & 19.20507 & 20 & 40.35571 & 11.68236 \\
\hline 6 & 55.61835 & 14.73695 & 21 & 46.73955 & 17.57642 \\
\hline 7 & 45.13639 & 14.80898 & 22 & 46.02411 & 21.52814 \\
\hline 8 & 39.32549 & 16.40341 & 23 & 46.03548 & 19.02615 \\
\hline 9 & 43.0058 & 11.76359 & 24 & 44.72122 & 14.41866 \\
\hline 10 & 39.03431 & 15.63687 & 25 & 41.51902 & 12.6475 \\
\hline 11 & 52.42991 & 17.34026 & 26 & 50.56492 & 16.98783 \\
\hline 12 & 44.31756 & 17.33379 & 27 & 35.56276 & 11.09193 \\
\hline 13 & 34.57597 & 12.51804 & 28 & 44.47722 & 17.97808 \\
\hline 14 & 40.84709 & 13.69591 & 29 & 47.45575 & 13.70641 \\
\hline 15 & 45.66464 & 15.91546 & 30 & 54.84107 & 22.0475 \\
\hline
\end{tabular}

\section{Experimental Results and Analysis}

The test results were linearly analyzed by SAS analysis software [14, 15]. The relationship between the filtration efficiency, resistance of electrospun nanofibres non-woven membrane and grammes per square metre of the fiber membrane, the thickness of the fiber membrane, the fiber diameter, and the porosity of the fiber membrane was analysed, as shown in Table 4. 
Table 4. Pearson correlation analysis results

\begin{tabular}{|c|c|c|c|c|c|c|c|}
\hline & & $\begin{array}{l}\text { Filtration } \\
\text { efficiency }\end{array}$ & Resistance & Porosity & Diameter & Thickness & $\begin{array}{l}\text { Grammes per } \\
\text { square metre }\end{array}$ \\
\hline $\begin{array}{l}\text { Filtration } \\
\text { efficiency }\end{array}$ & $\begin{array}{l}\text { correlation coefficient } \\
\text { significant test results }\end{array}$ & 1.00000 & $\begin{array}{l}0.98540 \\
<0.001\end{array}$ & $\begin{array}{c}-0.77471 \\
<0.001\end{array}$ & $\begin{array}{c}-0.73164 \\
<0.001\end{array}$ & $\begin{array}{c}0.51122 \\
0.0039\end{array}$ & $\begin{array}{c}0.46494 \\
0.0096\end{array}$ \\
\hline Resistance & $\begin{array}{l}\text { correlation coefficient } \\
\text { significant test results }\end{array}$ & $\begin{array}{l}0.98540 \\
<0.0001\end{array}$ & 1.00000 & $\begin{array}{l}-0.72423 \\
<0.0001\end{array}$ & $\begin{array}{c}-0.70019 \\
<0.0001\end{array}$ & $\begin{array}{c}0.58134 \\
0.0008\end{array}$ & $\begin{array}{c}0.44603 \\
0.0135\end{array}$ \\
\hline Porosity & $\begin{array}{l}\text { correlation coefficient } \\
\text { significant test results }\end{array}$ & $\begin{array}{c}-0.77471 \\
<0.0001 \\
\end{array}$ & $\begin{array}{c}-0.72423 \\
<0.0001 \\
\end{array}$ & 1.00000 & $\begin{array}{c}0.60195 \\
0.0004\end{array}$ & $\begin{array}{l}-0.22250 \\
0.2373 \\
\end{array}$ & $\begin{array}{c}-0.45252 \\
0.0120 \\
\end{array}$ \\
\hline Diameter & $\begin{array}{l}\text { correlation coefficient } \\
\text { significant test results }\end{array}$ & $\begin{array}{c}-0.73164 \\
<0.0001 \\
\end{array}$ & $\begin{array}{l}-0.70019 \\
<0.0001 \\
\end{array}$ & $\begin{array}{c}0.60195 \\
0.0004 \\
\end{array}$ & 1.00000 & $\begin{array}{c}-0.47037 \\
0.0087 \\
\end{array}$ & $\begin{array}{c}-0.50221 \\
0.0047 \\
\end{array}$ \\
\hline Thickness & $\begin{array}{l}\text { correlation coefficient } \\
\text { significant test results }\end{array}$ & $\begin{array}{c}0.51122 \\
0.0039 \\
\end{array}$ & $\begin{array}{c}0.58134 \\
0.0008 \\
\end{array}$ & $\begin{array}{c}-0.22250 \\
0.2373 \\
\end{array}$ & $\begin{array}{c}-0.47037 \\
0.0087 \\
\end{array}$ & 1.00000 & $\begin{array}{c}0.46056 \\
0.0104 \\
\end{array}$ \\
\hline $\begin{array}{c}\text { Grammes } \\
\text { per square } \\
\text { metre }\end{array}$ & $\begin{array}{l}\text { correlation coefficient } \\
\text { significant test results }\end{array}$ & $\begin{array}{c}0.46494 \\
0.0096\end{array}$ & $\begin{array}{c}0.44603 \\
0.0135\end{array}$ & $\begin{array}{c}-0.45252 \\
0.0120\end{array}$ & $\begin{array}{c}-0.50221 \\
0.0047\end{array}$ & $\begin{array}{l}0.46056 \\
0.0104\end{array}$ & 1.00000 \\
\hline
\end{tabular}


From the correlation analysis in Table 4, it can be seen that the changes of the filtration efficiency and resistance are obvious with the change of grammes per square metre, the change of thickness, the change of diameter and the change of porosity. Among them, the thickness of the fiber membrane, the fiber diameter, and the porosity of the fiber membrane have a greater influence on the filtration efficiency and resistance of electrospun nanofibres non-woven membrane.

\subsection{The influence of the thickness of fiber membrane}

From the correlation analysis in Table 4, it can be known correlation between thickness of the fiber membrane and filtration efficiency, resistance of electrospun nanofibres non-woven membrane is extremely significant. Based on the test results, the relationship between the thickness of fiber membrane and filtration efficiency, resistance is obtained, as shown in the Figure 5. By using the regression analysis of SAS software, it may be known that the $p$ values of the $\mathrm{F}$ test of quadratic fitting in Figure 5 are 0.0045 and 0.0004 , respectively. As can be seen from the figure, with the increase of the thickness of the fiber membrane, the filtration efficiency and the resistance of electrospun nanofibres non-woven membrane increase gradually. The reason is that the thickness of the fiber membrane and the amount of fibers increase with the increase of the weight of the electrospun nanofibres non-woven membrane and the separation and trapping of the fibers on the particles increases, so the filtration efficiency and the resistance of electrospun nanofibres non-woven membrane increase. 
RELATIONSHIP BETWEEN FILTRATION EFFICIENCY ... 141
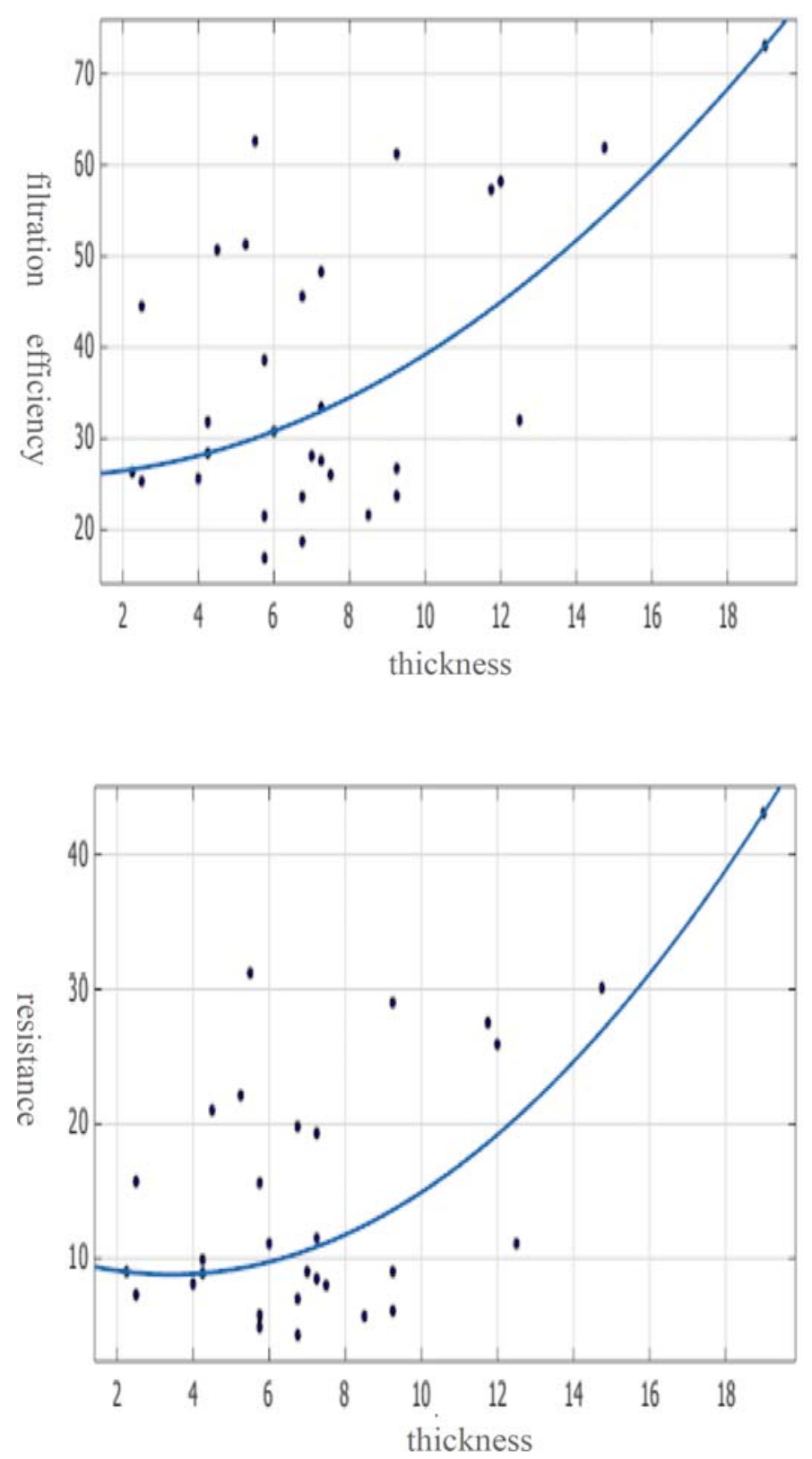

Figure 5. Relationship between the thickness and filtration efficiency, resistance. 


\subsection{The influence of the fiber diameter}

From Table 4, the Pearson correlation coefficients of the fiber diameter and filtration efficiency, resistance of electrospun nanofibres non-woven membrane are -0.73164 and -0.70019 , respectively. The results show that the fiber diameter has an extremely significant effect on filtration efficiency and resistance of electrospun nanofibres nonwoven membrane. Figure 6 shows the effect of the fiber diameter on filtration efficiency and resistance of electrospun nanofibres non-woven membrane, respectively. By using the regression analysis of SAS software, it may be known that the $p$ values of the $\mathrm{F}$ test of quadratic fitting in Figure 6 are 0.0001 and 0.0001, respectively. The results show that the larger the fiber diameter, the lower the filtration efficiency and the resistance of electrospun nanofibres non-woven membrane. The reason is that the thicker the fiber, the smaller the fiber surface area, the adsorption resistance of the fiber to the particles is weaker and the filtration efficiency and the resistance are lower. 
RELATIONSHIP BETWEEN FILTRATION EFFICIENCY ... 143
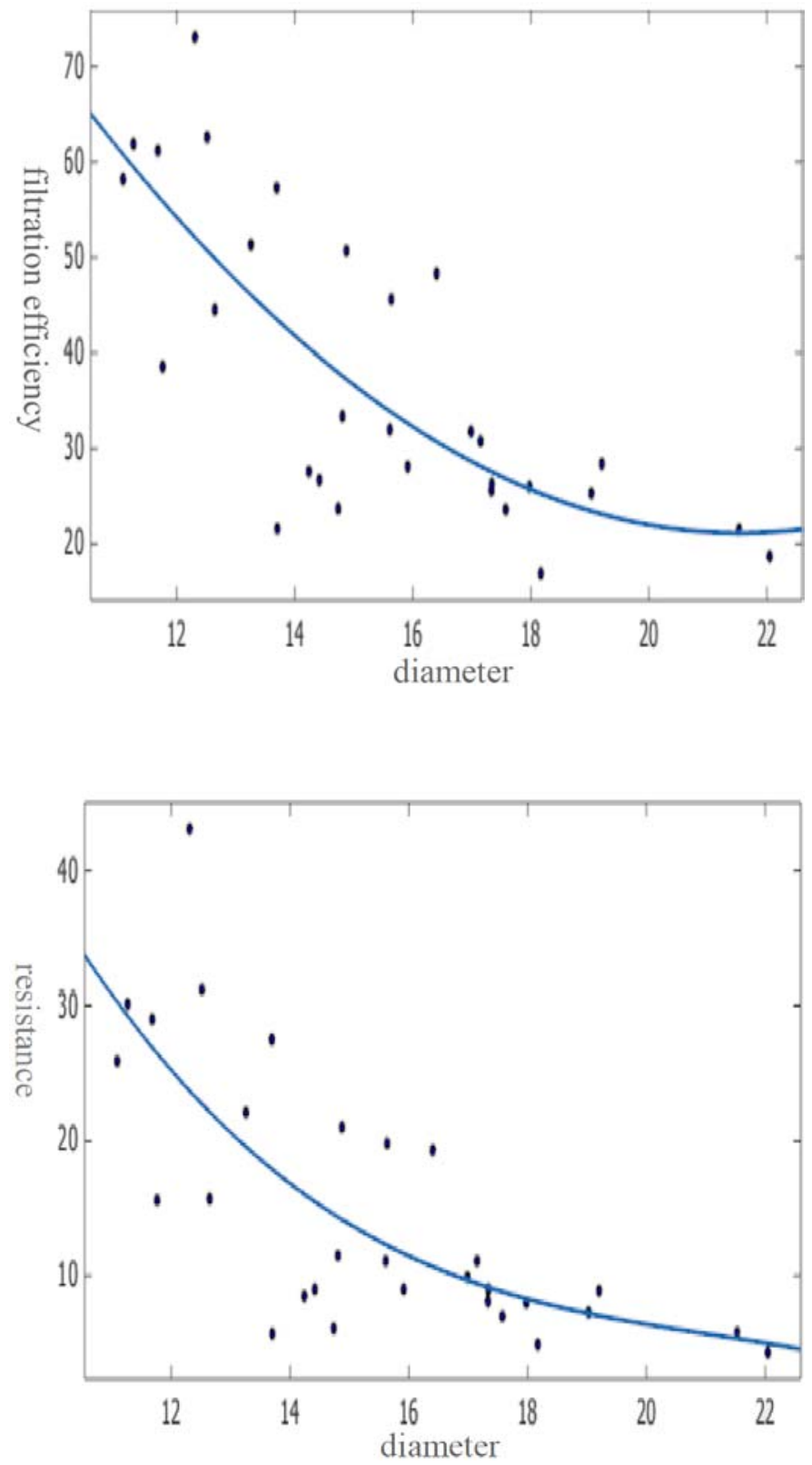

Figure 6. Relationship between the diameter and filtration efficiency, resistance. 


\subsection{The influence of the porosity of the fiber membrane}

As shown in Table 4, the Pearson correlation coefficients of porosity of the fiber membrane and filtration efficiency, resistance of electrospun nanofibres non-woven membrane are -0.77471 and -0.72423 , respectively, indicating that porosity is an extremely important factor affecting the filtration efficiency and resistance of electrospun nanofibres non-woven membrane. Figure 7 shows the relationship between porosity of the fiber membrane and filtration efficiency, resistance of electrospun nanofibres non-woven membrane, respectively. By using the regression analysis of SAS software, it may be known that the $p$ values of the $\mathrm{F}$ test of quadratic fitting in Figure 7 are 0.0001 and 0.0001, respectively. As can be seen from the figures, the smaller the porosity of the fiber membrane is, the higher the filtration efficiency and the resistance of electrospun nanofibres non-woven membrane are. Because the smaller the porosity of the fiber membrane is, the greater the fiber filling rate is, interference with particles in the air would be stronger, and capture efficiency would be higher. Then the filtration efficiency and the resistance of electrospun nanofibres non-woven membrane increase. 
RELATIONSHIP BETWEEN FILTRATION EFFICIENCY ... 145
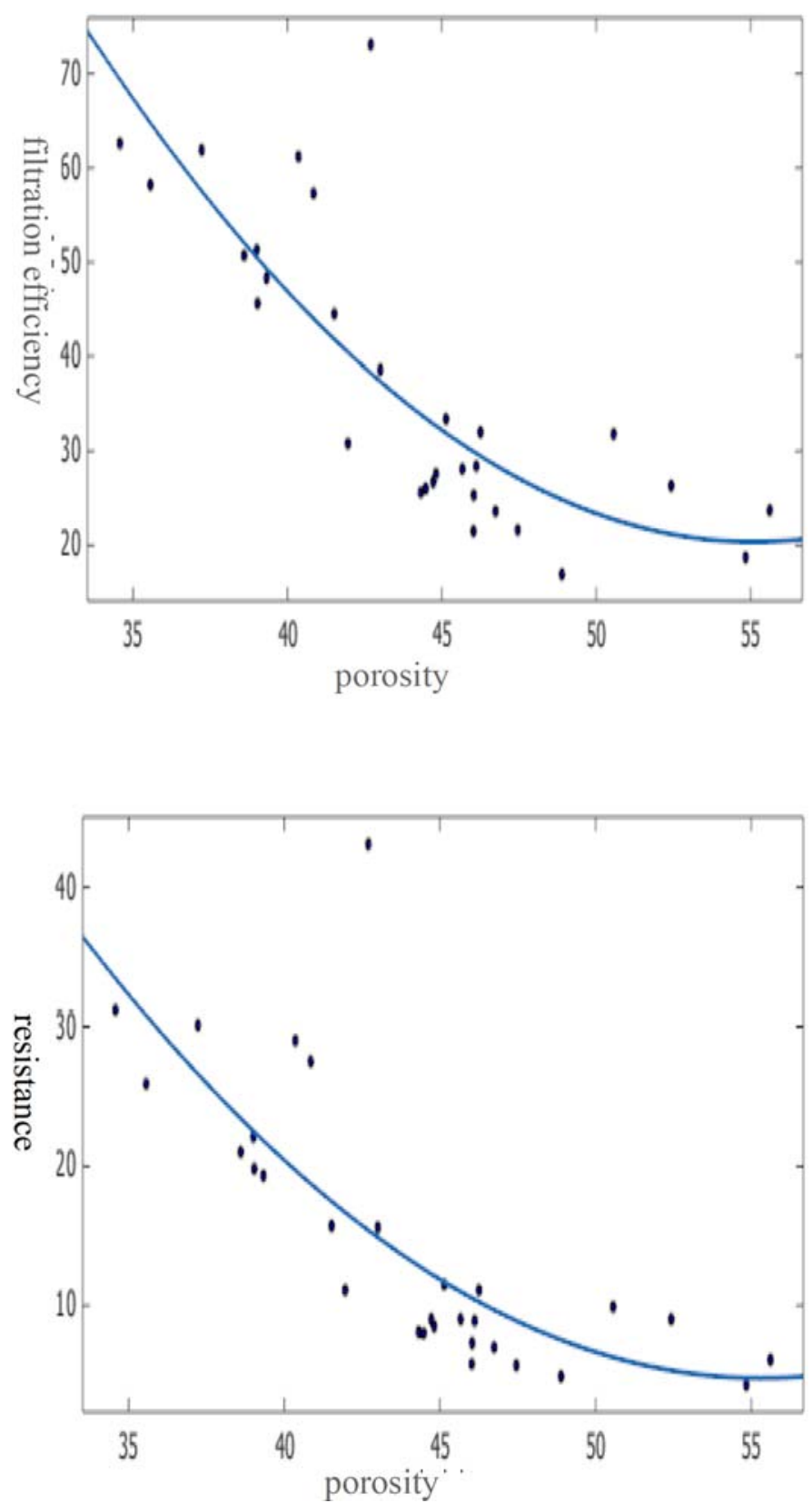

Figure 7. Relationship between the porosity and filtration efficiency, resistance. 


\subsection{The influence of the grammes per square metre of the fiber membrane}

From the correlation analysis in Table 4, it can be known that the Pearson correlation coefficients of thickness and filtration efficiency and resistance are 0.46494 and 0.44603 , and the significance tests are 0.0096 and 0.0135 , respectively. The effect of the grammes per square metre of the fiber membrane on the change of filtration efficiency and resistance is shown in Figure 8. By using the regression analysis of SAS software, it may be known that the $p$ values of the $\mathrm{F}$ test of quadratic fitting in Figure 8 are 0.0026 and 0.0019 , respectively. As can be seen from the figure, as increasing the grammes per square metre of the fiber membrane, the filtration efficiency and the resistance of electrospun nanofibres non-woven membrane increase gradually. However, when the grammes per square metre exceeds a certain value, the filtration efficiency will decrease and the resistance will drop. The reason is that with increasing grammes per square metre of the electrospun nanofibres

non-woven fabric fiber's separation and trapping of particles is strengthened. So filtration efficiency and resistance are increased. When the grammes per square metre is getting bigger and bigger, the separation and capture of the particles by the fibers will be weakened. This leads to a reduction in the filtration efficiency and the resistance. 
RELATIONSHIP BETWEEN FILTRATION EFFICIENCY ... 147
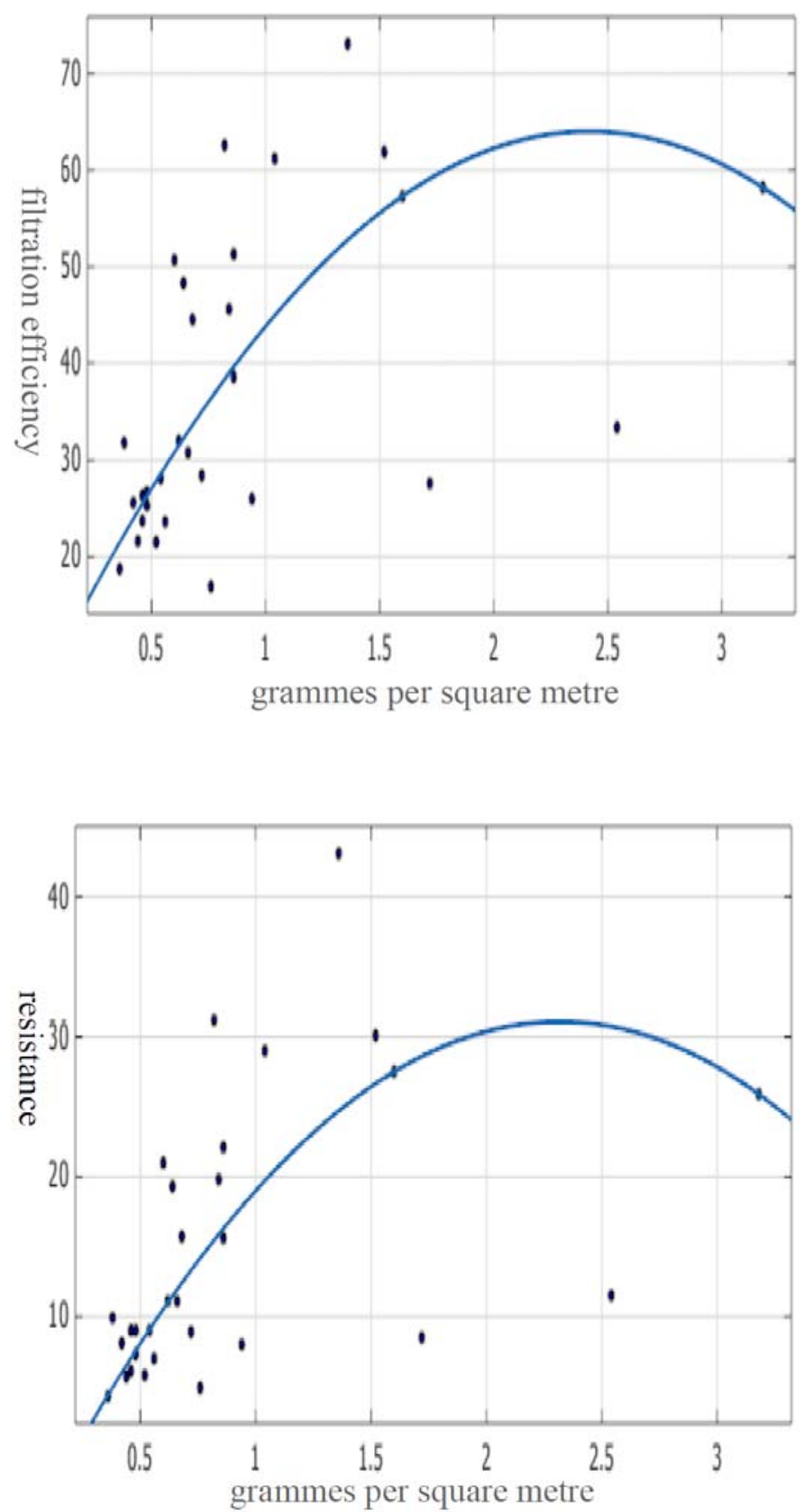

Figure 8. Relationship between the grammes per square metre and filtration efficiency, resistance. 


\section{Summary}

The effects of grammes per square metre of the fiber membrane, the thickness of the fiber membrane, the fiber diameter, and the porosity of the fiber membrane on the filtration efficiency and resistance electrospun nanofibres non-woven membrane are mainly described in this article. Firstly, the values of various parameters are tested, and then the thickness of the fiber membrane, the fiber diameter, and the porosity of the fiber membrane are analyzed by SAS software, it can be concluded that the change of key factors including the thickness of the fiber membrane, the fiber diameter and the porosity of the fiber membrane results in the changes of filtration properties and resistance. Of course, there is also a positive correlation between the grammes per square metre of the fiber membrane and the filtration efficiency, resistance electrospun nanofibres non-woven membrane. As the grammes per square metre of the fiber membrane increases, the thickness of the fiber membrane increases, the fiber diameter decreases and the porosity of the fiber membrane decreases, resulting in an increase in filtration efficiency and an increase in resistance.

\section{References}

[1] Weimin Kang, Bowen Chen, Xunpin Zhang et al., Electrospun nano-fiber composite membrane and its filtration properties, Textile Journal 27(10) (2006), 6-8.

[2] Kawabe Yazhang and Futing Liu, Characteristics and application of electrospun nonwovens, Technical Textiles 28(5) (2010), 38-42.

[3] Bingxuan $\mathrm{Ni}$ and Peng Zhang, Study on pore size distribution and filtration efficiency of nonwovens, Technical Textiles 3 (2012), 25-28.

[4] Yanhui Liu, Longmin Chen, Zhe Chen et al., The effect of thickness of melt blown nonwovens on its filtration performance, Technical Textiles 30(11) (2012), 17-20.

[5] Ruixin Li, Jingyang Peng, Ya Liu et al., Application of nonwovens in filtration, Nonwovens 19(6) (2011), 63-66.

[6] Haihua Yang and Xiangyu Jin, The application and developing trend of nonwoven filtering materials, Technical Textiles 5 (1998), 6-8.

[7] Jiaxiang Zhang, Development and application of nonwoven filtering materials, Technical Textiles 7 (1998), 9-11. 
RELATIONSHIP BETWEEN FILTRATION EFFICIENCY ... 149

[8] Meigui Peng and Bingchen Guo, New products and development trend of filtering materials, Nonwovens 11(1) (2003), 9-12.

[9] Yougang Dai and Baoqi Zuo, Overview of the electrospun nonwoven mats used as filtering materials, Technical Textiles 26(7) (2008), 1-6.

[10] Cailian $\mathrm{Qu}$ and Mingchi Dou, Application of nonwoven filtering material in automobile industry, Advanced Textile Technology 14(6) (2006), 60-62.

[11] Hao Chen, Mingliang Zhao, Jing Yang et al., Development and application of medical nonwoven filter materials, Melliand China 44(10) (2016), 44-46.

[12] Ye Li and Weimin Wang, Development and trend of nonwovens filter materials in 21 century, Nonwovens 11(1) (2003), 13-15.

[13] Yinnan Zhang, Current situation and developing trends of global market for nonwoven filter materials, China Textile Leader (s1) (2016), 7-18.

[14] Haibo Wang, Li Luo, Hailing Wang et al., SAS Statistical Analysis and Application: From Getting Started to Proficient, People Post Press, 2013.

[15] Yan Huang and Ping Wu, SAS Statistical Analysis and Application, Machinery Industry Press, 2006. 